\title{
JOÃO DA SILVA FEIJÓ viagem filosófica a Cabo Verde
}

\author{
María Estela Guedes \\ Centro Interdisciplinar de Ciência, Tecnologia e Sociedade da Universidade de Lisboa. \\ Av. Defensores de Chaves, $32-3 .^{\circ}-1000$ Lisboa
}

\section{SUMMARY}

The António Pusich's Memórias, published in 1956 by Orlando Ribeiro, really are the João da Silva Feijó's Ensaio económico sobre as Ilhas de Cabo Verde em 1797, presented to the Academia Real das Ciências de Lisboa. Feijó led one of the four Royal Expeditions organised by Domingos Vandelli to the Portuguese oversea's territories. We speak about his work and life in the Capeverdian archipelago.

\section{RESUMO}

Em 1956, Orlando Ribeiro publicou o Ensaio económico sobre as Ilhas de Cabo Verde em 1797, de João da Silva Feijó, como sendo as Memórias de António Pusich. A propósito da Expedição Régia ao arquipélago, uma das quatro que no séc. XVIII Domingos Vandelli organizou ao ultramar português, prestam-se algumas informações sobre a vida e trabalho de Feijó como naturalista.

\section{As MemóRias de (PUSICH) FEIJó}

O relatório publicado por Orlando Ribeiro ${ }^{1}$ como sendo as "Memórias de António Pusich", na verdade é o Ensaio económico sobre as Ilhas de Cabo Verde, de João da Silva Feijó ${ }^{2}$, publicado pela Academia Real das Ciências de Lisboa em 1815, mas

1 ORLANDO RIBEIRO (1956). As ilhas de Cabo Verde no princípio do século XIX. Memórias de António Pusich. Garcia de Orta, IV (4). Orlando Ribeiro foi reputado geógrafo. Em comum com JoÃo DA SILVA FEIJó, teve a oportunidade de estudar o vulcão da ilha do Fogo em actividade, dedicando-lhe a obra A Ilha do Fogo e as suas erupções. Memórias, Sér. Geográfica, I, Junta de Investigações do Ultramar, Lisboa, 1954.

2 JoÃo DA SILVA FeIJó (1815). Ensaio económico sobre as Ilhas de Cabo Verde. Memórias Económicas, Academia Real das Sciencias de Lisboa, V. Refiram-se também as memórias Sobre a Fábrica Real do Anil da Ilha de Santo Antão, ibid., I, 1789; Sobre a urzela de Cabo Verde, ibid., V, 1815; Memória sobre a última erupção vulcânica do Pico do Fogo... In: J. O. PIMENTEL (1857). Memória sobre a 
provavelmente lido nas sessões públicas em 1797. Nesta data, Feijó estava em Lisboa, finda a viagem filosófica. Segundo a interpretação de Orlando Ribeiro, Pusich pretendia com aquele relatório demonstrar que conhecia bem o arquipélago, sendo legítimo assim aspirar ao seu governo. De facto, António Pusich foi governador de Cabo Verde, de 1818 a 1822. Fiando-se em Sena Barcelos ${ }^{3}$, que diz ter Pusich publicado nas Memórias da Academia, Orlando Ribeiro, que encontrara certo manuscrito, publica-o como sendo de Pusich. Se estava assinado por este, trata-se de plágio. De outra maneira, poderá ser o Ensaio económico revisto e desenvolvido pelo próprio Feijó, para fim idêntico ao atribuído a Pusich. Há informação de que Feijó foi secretário do governo de Cabo Verde. Porém, os documentos consultados no Arquivo histórico do Museu Bocage (Museu Nacional de História Natural, Lisboa) dão-no-lo unicamente como naturalista. Se desempenhou funções políticas, isso só pode ter acontecido depois de terminada a exploração científica.

\section{NO TEMPO DE FEIJÓ}

Recuemos a 1772 para nos situarmos no contexto científico da época. Nesse ano, o Marquês de Pombal procedia em Coimbra à abertura solene da Universidade Reformada, que se pretendia anti-escolástica, prática, voltada para as necessidades económicas do país. As ciências davam entrada no ensino, após uma frustrada experiência no Colégio dos Nobres. Construiram se jardins botânicos, observatórios astronómicos, laboratórios, sendo o de Física considerado então o melhor da Europa. Vários mestres estrangeiros foram convidados para colaborar na reforma e leccionar os cursos, entre eles o paduano Domingos Vandelli, que assim se tornou o primeiro lente de História Natural e Química em Portugal. Anos depois, D. João Carlos de Bragança, duque de Lafões, o visconde de Barbacena (primeiro doutor saído da re-

produção do sulfato de sódia... Ibid., N.S., Cl. Sc. Mathem., Phys. Nat., II: I. Na colecção manuscrito azul, da biblioteca da Academia das Ciências de Lisboa, existe uma Flora Insulana da sua autoria, que aparentemente só foi usada por botânicos, nunca publicada em isolado. Outras fontes de informação sobre Feijó, inéditas, são as suas cartas e outros documentos existentes no Arquivo histórico do Museu Bocage (CN/F-1-22). Existe ainda neste Arquivo uma Explicação do modo de fazer a tinta azul com que se costuma tingir os panos em Cabo Verde, não assinada e não datada, em letra desenhada, com carimbo do Museu da Ajuda, que pertence a Feijó. Depois de regressar ao Rio de Janeiro, ali continuou o trabalho de naturalista. Há nas enciclopédias notícia de outros ensaios seus sobre pecuária e pro-dutos naturais brasileiros, faltando referência ao local de publicação, o que parece significar que se trata de comunicações que ficaram inéditas. Feijó nasceu no Rio de Janeiro em 1760 e morreu no Ceará em 1824. Bacharel em Matemática, foi professor da Academia Militar do Rio de Janeiro e sócio correspondente da Academia Real das Ciências de Lisboa.

3 J. C. SENNA BARCEllos (1806). Subsídios para a História de Cabo Verde e Guiné. Hist. Mem. Acad. R. Sci. Lisboa, NS, $2^{\mathrm{a}}$ Classe, X (2). 


\section{JOÃO DA SILVA FEIJÓ}

cém-criada Faculdade de Filosofia, aluno portanto de Vandelli), Abade Correia da Serra, notável botânico, e Domingos Vandelli, fundam a Academia Real das Ciências de Lisboa, cujos sócios provêm essencialmente do corpo docente e discente da Universidade. Estas duas instituições agem em coordenação com o Real Jardim Botânico da Ajuda num dos mais significativos empreendimentos científicos portugueses do séc. XVIII: as Expedições Régias, ou viagens filosóficas, organizadas por Vandelli, a alguns dos nossos territórios das conquistas. Assim, em 1783, para Moçambique e Goa, parte o naturalista Manuel Galvão da Silva; para Angola, Ângelo Donati e Joaquim José da Silva; para o Brasil, Alexandre Rodrigues Ferreira; para Cabo Verde, João da Silva Feijó.

O resultado científico destas expedições gorou-se em boa parte, não tendo constituído base a partir da qual os estudos continuassem. Há descontinuidades entre o esforço destes homens e o dos do séc. XIX, que não é lícito atribuir às sempre invocadas pilhagens dos exércitos de Napoleão, durante a Guerra Peninsular. Nem a pilhagem foi tão grave quanto a descrevem ${ }^{4} \mathrm{nem}$, a ter sido calamitosa, podia ter destruído trabalho publicado que, esse sim, é denegado nos períodos seguintes, gerando corte epistemológico entre gerações de cientistas.

Parte dos intelectuais ligados à Universidade e à Academia eram liberais, congregados na maçonaria, simpatizantes da causa europeia de Napoleão. Após a retirada dos exércitos franceses do nosso país, o grupo liberal dividiu-se, tendo os fundadores da Academia, sede do Grande Oriente ${ }^{4}$, sofrido perseguições de todo o tipo, caso mais flagrante de Vandelli. $O$ facto porém de os primeiros liberais serem revolucionários, e conservadores os do séc. XIX, não explica suficientemente a falta de verdade histórica com que estes trataram os antecessores, abrindo caminho a confusões que ainda hoje permanecem. Dá ideia de que o conflito é também religioso, próprio de uma Inquisição moribunda, no seio da qual a mão que risca é também a mão que escreve. Este paradoxo tem na política um reflexo em Pina Manique, estadista de primeiro plano, chefe máximo da Polícia, conhecido por perseguir implacavelmente jacobinos na pessoa de qualquer afrancesado ou inocente de que suspeitasse. No entanto, era a ele que directa ou indirectamente autênticos revolucionários recorriam, quando era preciso interceder por alguém. É facto bastante divulgado que Correia da Serra se teria exilado em Londres devido a perseguições do Intendente da Polícia,

4 M. Estela GuEDes (1995). Domingos Vandelli \& Agostinho de Macedo. Sol XXI, 12: 3-10. Um poema satírico de Agostinho de Macedo mostra que a Academia das Ciências era a sede da maçonaria portuguesa. Uma carta de Vandelli para D. João VI, então no Brasil, dá uma versão mais comedida do que a habitual dos produtos naturais levados do Real Museu da Ajuda para França, por mão de Geoffroy Saint-Hilaire. Memórias do lagarto caboverdiano (Macroscincus coctei), O Escritor, N.S., 1, 1991; Entre a fauna exótica de Cabo Verde, o grande scinco do Levante; sumário no Libro de Resumos do V Simposio de Historia e Ensino das Ciencias, Vigo, Setembro de 1995. 


\section{MARÍA ESTELA GUEDES}

que o considerava um perigoso jacobino. A verdade porém é que o político era respeitado pelos intelectuais, e mantinha com eles boas relações. Vandelli recorre a Correia da Serra para salvar um amigo da cadeia, dadas as relações de amizade entre o Botânico e Pina Manique 5 .

É neste contexto das Luzes, aliás já tocado pelo romantismo, bastante complexo nas suas interligações políticas, religiosas e científicas, que se insere a actividade de Feijó em Cabo Verde. A documentação que lhe diz respeito, existente no Museu Bocage, logo à data de chegada no-lo mostra perseguido. Alguém em Cabo Verde estaria à sua espera para o matar, tal como pouco antes havia assassinado o bispo D. Frei Francisco de S. Simão. Ora uma pergunta que invariavelmente fazem os historiadores da ciência do séc. XVIII é acerca das ligações de pessoas reais à maçonaria, uma vez que elas eram vulgares nas cortes europeias ${ }^{6}$. As Expedições Régias estavam sob o patrocínio do príncipe D. José, cuja morte, em 1788, tem suscitado interrogações. Há quem não acredite ter ele sucumbido à varíola, suspeitando que se tratou de assassínio devido a ligações maçónicas ${ }^{6}$.

\section{FeIJó EM CABo VERDE}

Antes de partir para África, findo o curso de História Natural na Faculdade de Filosofia, Feijó fez o reconhecimento das minas de carvão de Buarcos, na companhia de Alexandre Rodrigues Ferreira, isto no âmbito do estudo das produções naturais no Reino, promovidas por Vandelli. Era brasileiro, muito jovem à data de partida para a viagem filosófica - 23 anos apenas. Feijó era muito jovem e não estava na sua terra, nem em Portugal nem em África. Neste contexto, é difícil ver nele o facínora cujos crimes eram dignos da prisão do Limoeiro, como pretende aquele Barcelos que diz ter Pusich publicado nas Memórias da Academia, mas se esquece das referências bibliográficas, e que fala de Feijó como estando em Cabo Verde já em 1781, quando o facto de todos os naturalistas terem partido em 1783 está inequivocamente comprovado.

Cabo Verde era local, como S. Tomé e Angola, para onde se deportavam condenados pela polícia política e Inquisição. Segundo Barcelos, a dado momento Feijó trava relações com elementos da nobreza que para o arquipélago tinham sido deportados, e se envolvem em revoluções locais. Ora os desterrados políticos eram geralmente jaco-

5 C. AYres (1917-1927). Para a História da Academia das Sciencias. Bolm. Segunda Classe, Acad. Ciên. Lisboa, XII a XV; XVII.

6 Gerhard SAILlER (1995). A Academia das Ciências de Lisboa no séc. XVIII e o seu fundador, o Duque de Lafões. Seminário do Centro Interdisciplinar de Ciência, Tecnologia e Sociedade da Universidade de Lisboa, 28. 5. O autor apresenta o Duque de Lafões como maçon, suspeitando de que outros membros da família real também o tivessem sido. Em publicação na Ingenium. 
binos, o que torna as ligações de Feijó muito perigosas. Também Joaquim José da Silva se encontrará em Angola ${ }^{7}$ com Álvares Maciel ${ }^{8}$, desterrado em Massangano, o que dá uma curiosa ligação, neste caso apadrinhada por entidades governamentais.

Feijó era militar de carreira, será coronel de artilharia ao regressar ao Rio de Janeiro, mas não vamos agora supor que, pelo facto de ter preparação para a guerra, isso lhe dava alguma aptidão especial para se tornar um criminoso, mal desembarcou em S. Nicolau. No arquipélago, afirma Barcelos, o naturalista tratava os escravos com despotismo e arrogância, e cometera latrocínio na administração pública. Não é possível. Feijó não tinha qualquer poder como naturalista nem acesso à administração, com a qual aliás entra em litígio, por as suas remessas não serem embarcadas. Pelo menos nos quatro primeiros anos, a sua existência foi miserável. Não recebia qualquer ordenado, de Lisboa diziam-lhe que havia ordem do ministro da Marinha e Ultramar, Martinho de Melo e Castro, para ser pago na província, aqui declaravamlhe que não havia ordem nenhuma, e, mesmo que houvesse, ninguém lhe pagaria por ordem de Melo e Castro, só por ordem do marquês de Angeja, ministro da Fazenda. $\mathrm{Na}$ perspectiva do naturalista, o seu único protector era Júlio Mattiazzi, jardineirochefe do Real Jardim Botânico da Ajuda, que por caridade lhe socorria em Lisboa a esposa e um filho de tenra idade. É de crer que a correspondência de Júlio Mattiazzi fosse interceptada, ou este não se arriscasse a escrever, pois as cartas de Feijó a pedir socorro acusam a sistemática falta de resposta. Estava desamparado, à mercê da prepotência do governo local, sem meios para proceder às exploração e nem sequer para subsistir. Seguindo a correspondência que trava sem feed back, à excepção de uma carta $^{9}$ oriunda talvez do Real Museu da Ajuda, mas que tudo indica ter sido escrita sob pressão de Martinho de Melo e Castro, cuja extrema dureza quanto à incompe-

7 G. SousA DIAS (1930). José de Anchieta. Pelo Império, 58. Lisboa. José Álvares Maciel e Joaquim José da Silva foram encarregados de verificar se no território de Ambaca havia minas de ouro, mas infelizmente só encontraram esmeril de má qualidade.

8 José Álvares Maciel, cujo nome se liga à exploração científica de Angola, formara-se na Faculdade de Filosofia. Vandelli, seu mestre, encarregou-o do estudo mineralógico da Serra da Estrela. Imbuído das ideias do grupo liberal coimbrão, de regresso ao Brasil, sua terra natal, empenha-se na causa da independência. Será o ideólogo republicano do Tiradentes, na Inconfidência Mineira (1789), conjura que visava tornar Minas Gerais um estado independente. Condenado à morte, a pena é substituída por desterro para Angola, onde morre em 1804. Um dos feitos mais notáveis da sua vida de estudante foi a colaboração no fabrico dos primeiros balões a hidrogénio lançados em Portugal. Tratou-se de experiências escolares levadas a cabo por instância de Vandelli, no laboratório de Química, em 1784.

9 Cópia de carta para Feijó, não assinada, de 1785, aludindo a instruções e exigências de Martinho de Melo e Castro. A principal preocupação do governo era averiguar que riquezas naturais podiam ser exploradas para a indústria na ilha do Fogo, considerada a mais interessante dado o vulcanismo activo, em especial enxofre. Feijó devia permanecer um ano em cada ilha e remeter exemplares de todas as espécies para o Real Museu da Ajuda, bem como prestar informações sobre a pesca, possibilidade de explorar a planta da goma arábica e outras produções úteis. Arquivo histórico do Museu Bocage, CN/F-13. 
tência de Feijó deixa dúvidas sobre o verdadeiro motivo das críticas, os anos passados em Cabo Verde foram para este homem "um degredo sem nenhum crime haver cometido", nas suas próprias palavras. Miséria, doença, humilhação, profunda infelicidade. E esta é uma imagem de Feijó que contraria a de Barcelos, divulgada mesmo por estrangeiros, caso da obra de Link e Hoffmansegg ${ }^{10}$, se bem que este livro não seja de todo inocente nas intenções. Está na origem de calúnias sobre Vandelli, contradiz-se nas várias traduções acerca do valor do museu do Real Jardim Botânico da Ajuda, despertou o interesse de Napoleão pelo património cultural português, talvez também espanhol. Em termos literários, o seu valor é medíocre, a informação nele contida não justifica que se tenha tornado um best seller, com edições sucessivas em Inglaterra, França e Alemanha, pelo menos. Sob a capa da exploração botânica, estes dois alemães vieram certamente à Península Ibérica fazer espionagem, o que não era invulgar. Também os naturalistas portugueses em África e Brasil levavam instruções secretas.

Em carta de 27.7.1788, quando recolhia colaborações entre colegas e discípulos para as Memórias a estrear no ano seguinte pela Academia, Vandelli escreve a Abade Correia da Serra, então secretário da instituição: "Entretanto lhe remeto algumas memórias que me mandou ultimamente o pobre, desprezado, perseguido e escravo Feijó, das ilhas de Cabo Verde" . Esta frase, de um liberal para outro, contraria as informações de Barcelos, e dá-nos motivo para não desistirmos de buscar a verdade.

\section{DOIS TRABALHOS PIONEIROS}

São poucos os ensaios de Feijó publicados nas Memórias da Academia, e todos eles em data muito posterior à redacção. No entanto, a partir das informações e amostras remetidas, foi possível a outros publicarem resultados da expedição. Caso mais notório de Vandelli11 , com as suas memórias sobre as produções das conquistas, em que inclui algumas de Cabo Verde, e em especial a que se refere ao sal gema.

Das memórias de Feijó, há a salientar, além do Ensaio económico, a Memória sobre a erupção vulcânica do Pico da Ilha do Fogo sucedida em 24 de Janeiro do ano de $1785 . .$. , e terminada dois meses após. Este ensaio teria corrido o risco de ficar inédito se Pimentel ${ }^{2}$, em 1857, não o tivesse salvo do esquecimento, inserindo-o em trabalho seu, por se ter admirado com um facto que julga notável: o de Feijó, natura-

10 F. H. LiNK (1803). Voyage en Portugal, depuis 1797 jusqu'en 1799. Paris.

11 Domingos VANDELli (1789). Memória sobre algumas produções naturais das Conquistas, as quais ou são pouco conhecidas, ou não se aproveitam. Mem. Econ. Acad. R. Sci. Lisboa, I; Memória sobre as produções naturais deste Reino, e das Conquistas, primeiras matérias de diferentes fábricas, ou manufacturas. Ibid., I; y (1812). Memória sobre o sal gema das Ilhas de Cabo Verde. Ibid., IV. 
lista do séc. XVIII, já conhecer ao natural o sulfato de sódia, componente da pólvora, de extrema necessidade na indústria militar, mas que ficava caro por ser produzido artificialmente nas fábricas.

Em geral considera-se que os primeiros estudos do vulcanismo em Cabo Verde datam do séc. XIX, ignorando-se que essa área da ciência foi uma das que ocuparam os naturalistas a partir da reforma da Universidade, em 1772, quer no que diz respeito ao estudo do território português, quer ultramarino. Há notícias sobre as erupções do Fogo desde pelo menos o séc. XVI, mas o ensaio de Feijó é o pioneiro em moldes de ciência moderna.

Também o Ensaio económico é o primeiro relatório geral que aparece sobre Cabo Verde. Pequeno, mas suficientemente importante para ter sido plagiado e servido de modelo a quantos se seguiram sobre o ultramar em geral ou sobre o arquipélago em particular. Muitas observações de Feijó serão reproduzidas quase textualmente por autores das gerações seguintes, sem referência à fonte. Citando os seus próprios subtítulos, nota-se que Feijó, embora assumindo-se apenas como fisiocrata, deixando para memórias futuras a História Natural, fala de tudo, característica da formação global do cientista da época, ou filósofo natural - Da população (dados demográficos, morais, etnográficos, linguísticos, psicológicos), Da cultura (o milho, o feijão, o café), Das artes e manufacturas (tecelagem, tinturaria, cortumes, fábricas, extracção do sal gema) e Do comércio.

Neste ponto, o do comércio, fornece informações da maior relevância sobre algo que hoje é desconhecido da maior parte dos que nestes assuntos se ocupam - em tempos, um dos maiores comércios de Cabo Verde fora o da tartaruga viva e salgada, para refresco dos navios franceses, ingleses e espanhóis, que das colónias da Senegâmbia e Golfo da Guiné se dirigiam para as da América, em especial Antilhas. A carne de tartaruga era barata, com ela se alimentavam os escravos em Cabo Verde.

Logo a abrir o Ensaio, Feijó presta uma informação polémica: "No descobrimento das Ilhas de Cabo Verde, havendo-se unicamente encontrado povoada a de S. Tiago de Negros Jalofos (que ali tradicionariamente consta terem passado por acaso, perseguidos pelos Felupos seus vizinhos, e lançados pelas Brizas e Correntes ao Oeste...)". Não era decerto a ilha de Santiago, todos os mareantes são unânimes ao afirmarem que essa ilha estava despovoada. Na versão do Ensaio atribuída a Pusich, a ilha povoada é S. Nicolau, a NW, por sinal a mais próxima dos ilhéus Branco e Raso, onde vivia o grande scinco do Levante, Macroscincus coctei (Sauria: Scincidae), lagarto gigante que apaixonou muitos exploradores europeus do séc. XIX, foi uma das espécies de cativeiro mais solicitadas, e ainda hoje desperta tanta curiosidade científica como Lacerta simonyi das Canárias. Conhecida do Norte de África, introduzida provavelmente a partir do Egipto, esta espécie está ligada ao nome de Feijó, ao qual se atribui a sua descoberta em Cabo Verde ${ }^{4}$, se bem que nada no seu espólio nos autorize a tal pensar, uma vez que para todos os sáurios só usa o nome lagartos. A insis- 
tência com que se referem capturas de lagartos, em especial em Santo Antão e ilha do Fogo, autoriza-nos porém a pensar que esses animais despertaram não só o interesse de Feijó como de quem os solicitava de Lisboa, porventura Vandelli.

Há no arquipélago enigmas zoológicos (pombos mansos, "tartarugas de que gafos saram", lagartos verdes, de que falam os primeiros mareantes, bem como o grande scinco do Levante e espécies de géneros circum-mediterrâneos) ${ }^{12}$ que parecem provar a verdade da tradição de povoamento relatada por Feijó. As ilhas tinham sido no mínimo frequentadas, se não já habitadas, antes do séc. XVI. E não por vikings, fenícíos ou romanos, os povos usualmente invocados nestas circunstâncias, sim em épocas mais recentes pelos mouros da costa fronteiriça, cujas caravanas de camelos atravessavam o Sara para troca de produtos comerciais com o Egipto.

O maior mistério de Cabo Verde é porém outro: os descobridores referem-se a um rio, em Santiago ou Boavista, suficientemente largo e fundo para nele terem entrado com as caravelas. Hoje não há ali rio nenhum, só ribeiras temporárias, e trágicas secas de anos consecutivos, que pela fome reduziam a um terço a população, no tempo de Feijó. Supondo que seja verídica esta informação, como se explica que um rio desapareça da noite para o dia?

12 A. Mendes Correia (1954). Ultramar Português. II - Ilhas de Cabo Verde. Lisboa. 